\title{
Assessment on the Occupational Exposure of Manufacturing Workers to Dechlorane Plus through Blood and Hair Analysis
}

\author{
Haidong Zhang, ${ }^{\dagger \dagger} \mathrm{Pu}$ Wang, ${ }^{\dagger}$ Yingming $\mathrm{Li}^{\dagger}{ }^{\dagger}$ Hongtao Shang, ${ }^{\dagger}$ Yawei Wang, ${ }^{\dagger}$ Thanh Wang, $^{\dagger}$ \\ Qinghua Zhang, ${ }^{* \dagger}$ and Guibin Jiang ${ }^{\dagger}$ \\ ${ }^{\dagger}$ State Key Laboratory of Environmental Chemistry and Ecotoxicology, Research Center for Eco-Environmental Sciences, \\ Chinese Academy of Sciences, Beijing 100085, China \\ ${ }^{\ddagger}$ Department of Geography and Environment, Baoji University of Arts and Sciences, Baoji 721013, Shaanxi, China
}

\begin{abstract}
Dechlorane Plus (DP), as a widely used flame retardant in different electrical and textile applications, has recently attracted great concern around the world. The present study investigated the DP levels and distribution in human samples from a DP manufacturing plant and a nearby area in east China. The DP concentrations ranged from 89.8 to $2958 \mathrm{ng} / \mathrm{g}$ lipid weight in whole blood and 4.08 to $2159 \mathrm{ng} / \mathrm{g}$ dry weight in hair. For the workers engaged in DP manufacturing process, their DP levels were significantly higher than those in most of the other two control groups from the nearby area. The values of anti-DP fractional abundance ( $f_{\text {anti }}$ ratio) were commonly lower in the human samples from both the manufacturing plant and nearby area

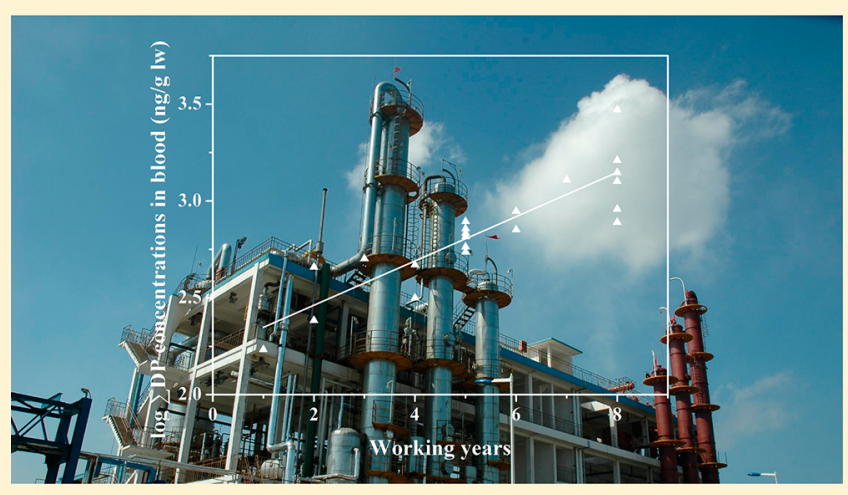
compared with those in the commercial products, and excretion as well as biotransformation are possible reasons for stereoselective accumulation of the syn-DP isomer in humans. Furthermore, a significantly positive relationship $(p<0.05)$ was obtained between (i) the concentrations (and $f_{\text {anti }}$ ) in the paired blood and hair samples, indicating a similar distribution pattern of the two DP isomers in the paired samples; (ii) the DP levels in human body and the exposure time $(p<0.05)$, which suggests that further assessment could be needed to investigate potential long-term risks to the occupational population.
\end{abstract}

\section{INTRODUCTION}

As several currently-used flame retardants (FRs), such as commercial pentabromodiphenyl ether (pentaBDE) and octabromodiphenyl ether (octaBDE), have recently been regulated by the Stockholm Convention, there are increasing market demands for alternative FRs. Dechlorane Plus (DP, chemical formula $\mathrm{C}_{18} \mathrm{H}_{12} \mathrm{Cl}_{12}$, CAS No, 13560-89-9) has emerged as an alternative substance to decabromodiphenyl ether (decaBDE) in polymeric applications in electrical and electronic equipment. ${ }^{1}$ DP has been used as an additive chlorinated flame retardant since the 1960s, and the annual global production volume is estimated at 5000 tons. ${ }^{2}$ It has been categorized as a high-production-volume (HPV) chemical and is included in the Canadian Domestic Substance List. Commercial DP products comprise of two isomers (syn-DP and anti-DP), both having structural features, such as the chlorinated norbornene moiety, similar to a number of persistent organic pollutants (POPs) such as Aldrin, Chlordane, Dieldrin, Endrin, Heptachlor, and Mirex. ${ }^{3}$ As an additive FR, DP is not covalently bonded to the material and could thus risk migrating out of the product during use or disposal.

Previous studies have shown that DP has typical features of a POP, such as bioaccumulation potential, ${ }^{4-8}$ persistence in the environment, ${ }^{9,10}$ and long-range transport potential toward remote regions. ${ }^{11}$ However, limited toxicity data have been obtained so far. ${ }^{12-14}$ Some recent researches show that DP exposure induced oxidative stress and damage to mouse livers across all tested concentrations, ${ }^{14}$ suggesting that DP exposure can cause liver impairment.

The occurrence of DP in the environment was first reported in 2006 in the Great Lakes region. ${ }^{15}$ Since then, many research studies have been carried out involving different environmental matrixes and biota samples. ${ }^{16,17}$ Many studies have shown higher DP concentrations in air, ${ }^{15,18-20}$ soil, ${ }^{19}$ sediment, ${ }^{21}$ and tree bark near manufacturing plants, ${ }^{22}$ suggesting that commercial production may be an important pathway for DP to enter the environment. However, DP is considered highly lipophic, persistent, and bioaccumulative in the food chain. ${ }^{4,6}$ It was found in tissues of high trophic level organisms. ${ }^{23-25}$ As for human tissues, Shabana et al. studied DP and polybrominated diphenylethers (PBDEs) in human milk from two Canadian cities, and the levels were in the range from not detectable to $8.0 \mathrm{ng} / \mathrm{g}$, which were two to ten times lower than those of the major PBDEs including BDE-209. ${ }^{26}$ However, there is currently

Received: March 15, 2013

Revised: July 10, 2013

Accepted: August 6, 2013

Published: August 6, 2013 
limited data on source-related human exposure. For example, Ren et al. ${ }^{27}$ studied DP in human serum in e-waste dismantling area in southeast China and found an obviously higher DP concentration in e-waste dismantling workers than that of the people in control area. In addition, Zheng et al. ${ }^{28}$ also found relatively higher DP concentration in human hair in e-waste recycling area as well as in indoor dust, suggesting that e-waste recycling activities could cause contamination of DP in the surrounding environment and that dust is one of the major pathways for DP exposure. Recently, Ben et al. ${ }^{29}$ investigated DP in the human blood and milk from Taizhou area, an e-waste recycling site in China and the results showed that DP levels in long-term residents of the local area ( $>20$ years) were significantly higher than the others ( $<3$ years). To our knowledge, there are no studies reporting on the human exposure to DP during DP manufacturing process.

In the present study, a total of 47 human blood and 43 hair samples were collected from both the occupationally exposed workers and nonoccupationally exposed population around a DP manufacturing plant in east China. The objective was to investigate the levels and distribution of DP in humans and provide important information for human risk assessment of occupational workers and the surrounding population from DP manufacturing process.

\section{MATERIALS AND METHODS}

Materials. The organic solvents ( $n$-hexane, dichloromethane (DCM)) were of pesticide grade and from J.T.Baker (NJ, U.S.). Nonane (chromatographic grade) was purchased from Sigma-Aldrich (U.S.). Anhydrous sodium sulfate was purchased from Beijing Chemical Factory (P.R. China). Silica gel 60 (70-230 mesh) was purchased from Merck (Darmstadt, Germany) and baked at $550{ }^{\circ} \mathrm{C}$ for $12 \mathrm{~h}$ in a muffle furnace before use. Individual standards for syn-DP, anti-DP $(50 \mu \mathrm{g} / \mathrm{mL}$, in toluene, purity >95\%) and ${ }^{13} \mathrm{C}_{12}$-PCB-138, ${ }^{13} \mathrm{C}_{12}$-PCB-209 were supplied by Wellington Laboratories (Guelph, ON, Canada). Four commercial DP products were supplied by the DP manufacturing plant. Sterile anticoagulated bovine whole blood was purchased from Perfemiker (Shanghai, P.R. China). Hair samples used as spiked matrixes were obtained from a barbershop close to Research Center for Eco-Environmental Sciences (Beijing, P.R. China).

Sample Collection. The plant is located in east China and has a DP production of about 500 tons per year. Three types of commercial products, DP-25, DP-35, and DP-515, are produced in this plant, which are similar to the products by Oxychem (NY, U.S.). ${ }^{12}$ These products are all the same compound, differing only in particle size. A total of 47 human blood and 43 hair samples were collected from both occupationally exposed workers and nonoccupationally exposed groups. Among them, 42 pairs of the samples including blood and hair were obtained to investigate the relationship of DP concentrations in individual subjects. The first group (Group A) consisted of 24 DP workers directly engaged in DP manufacturing, grinding, transportation, and packing processes; the second group (Group B) consisted of 12 workers from the same plant but engaged in other activities without direct DP contact; the third (Group C) consisted of 12 people who did not work in the DP plant and resided about $3 \mathrm{~km}$ from the manufacturing plant. Group A therefore represented the direct occupationally exposed workers, whereas Groups B and C could reflect the indirect or nonoccupationally exposed conditions.

Whole blood samples $(20 \mathrm{~mL})$ were collected from volunteers by medical professionals in November 2011 using BD Vacutainer serum tubes (with clotting agent and polymer separator). Hair samples were collected during the same period. The volunteers were required to wash their hair before collection, and then about 2-3 g samples were cut and wrapped with aluminum foil. All of the samples were kept at $4{ }^{\circ} \mathrm{C}$ and shipped back to the laboratory using an icebox and were stored at $-20{ }^{\circ} \mathrm{C}$ until analysis. Each volunteer participating in this study has given written consent. The information regarding age, gender, and years of work in DP manufacture was obtained by a questionnaire.

Sample Preparation. Hair samples were washed with Milli-Qwater, freeze-dried, and cut into short pieces $(2-3 \mathrm{~cm})$. Approximately $2 \mathrm{~g}$ hair samples were weighed and spiked with ${ }^{13} \mathrm{C}_{12}$-PCB-209. The extraction was performed on an accelerated solvent extraction (ASE 300, Dionex, U.S.). A mixture of $n$-hexane: DCM $(1: 1, \mathrm{v} / \mathrm{v})$ was used as the extraction solvent at $100{ }^{\circ} \mathrm{C}$ and $1500 \mathrm{psi}$. The clean-up process was based on previous study. ${ }^{30}$ Briefly, the extract was concentrated and loaded into a multilayer silica column (packed with $1 \mathrm{~g}$ neutral silica, $4 \mathrm{~g}$ basic silica, $1 \mathrm{~g}$ neutral silica, $8 \mathrm{~g}$ acid silica, $2 \mathrm{~g}$ neutral silica, $4 \mathrm{~g}$ anhydrous sodium sulfate from the bottom up) for cleanup. The column was preconditioned with $80 \mathrm{~mL} n$-hexane and eluted with $100 \mathrm{~mL} n$-hexane. The final eluent was concentrated into $20 \mu \mathrm{L}$ nonane and spiked with the injection standard $\left({ }^{13} \mathrm{C}_{12}\right.$-PCB-138).

For the whole blood samples, the extraction process followed some previously established methods, ${ }^{31,32}$ with minor modifications. Briefly, $5 \mathrm{~g}$ whole blood was mixed with $100 \mathrm{~g}$ anhydrous sodium sulfate and then homogenized. Prior to extraction, $1 \mathrm{ng}$ ${ }^{13}$ C-PCB-209 was spiked into the sample. The extraction was performed with an open column and eluted with $400 \mathrm{~mL} n$ hexane: DCM $(1: 1, \mathrm{v} / \mathrm{v})$. After lipid determination with gravitational method, the extract was subject to a multilayer silica column for further cleanup as described above. The final extract was concentrated into $20 \mu \mathrm{L}$ nonane and spiked with $1 \mathrm{ng}$ injection standard $\left({ }^{13} \mathrm{C}_{12}\right.$-PCB-138) for instrumental analysis.

An aliquot of $0.1 \mathrm{~g}$ technical DP product was dissolved in toluene and diluted to a concentration of $0.5 \mathrm{ng} / \mu \mathrm{L}$. Ten $\mu \mathrm{L}$ of surrogate standard $\left({ }^{13} \mathrm{C}-\mathrm{PCB}-209\right)$ was mixed with $10 \mu \mathrm{L}$ of the diluent for instrumental analysis to calculate the anti-DP fractional abundance.

GC/MS Analysis. The samples were analyzed using a gas chromatograph/mass spectrometer (GC/MS, SHIMADZU 2010 Ultra, Japan) with an electron capture negative ionization (ECNI) ion source. The injection $(1 \mu \mathrm{L})$ was performed in splitless mode, and the detection was in SIM mode. The injection port and the transfer line were held at $285{ }^{\circ} \mathrm{C}$. The ion source temperature was $200{ }^{\circ} \mathrm{C}$. The carrier gas was helium and the reagent gas was methane. A $15 \mathrm{~m}$ DB-5MS capillary column $(0.25 \mathrm{~mm}$ i.d. $\times 0.1 \mu \mathrm{m}$ film thickness, J\&W Scientific, U.S.) was used for chromatographic separation with a constant flow rate of $1 \mathrm{~mL} / \mathrm{min}$. The GC temperature program was as follows: hold at $100{ }^{\circ} \mathrm{C}$ for $4 \mathrm{~min}$; then increase to $150{ }^{\circ} \mathrm{C}$ at $8{ }^{\circ} \mathrm{C} / \mathrm{min}$ and hold for $4 \mathrm{~min}$; finally ramp to $300{ }^{\circ} \mathrm{C}$ at $12{ }^{\circ} \mathrm{C} / \mathrm{min}$ and hold for $13 \mathrm{~min}$. The following ions were monitored: $\mathrm{m} / z 653.8$ and 651.8 for DP, $m / z 369.7$ and 371.7 for ${ }^{13} \mathrm{C}_{12}$-PCB-138, and $\mathrm{m} / z 507.9$ and 509.9 for ${ }^{13} \mathrm{C}_{12}$-PCB-209.

Quality Assurance/Quality Control. There were no DP detected in both bovine blood blank and hair blank samples. 500 pg technical DP and $1 \mathrm{ng}{ }^{13} \mathrm{C}-\mathrm{PCB}-209$ were spiked into about $5 \mathrm{~g}$ bovine blood and $2 \mathrm{~g}$ hair samples. Recoveries of spiked DP were $89.7 \% \pm 9.4 \%$ and $92.3 \% \pm 5.3 \%$ (mean \pm SD, $n=6$ ) in bovine and hair, respectively. Recoveries of surrogate standard ${ }^{13} \mathrm{C}_{12}$-PCB-209 for spiked bovine blood and hair samples were $91.2 \pm 12.8 \%$ and $89.7 \pm 15.2 \%$ (mean \pm SD, $n=6$ ). Limit of detection (LOD) was defined as signal-to-noise 

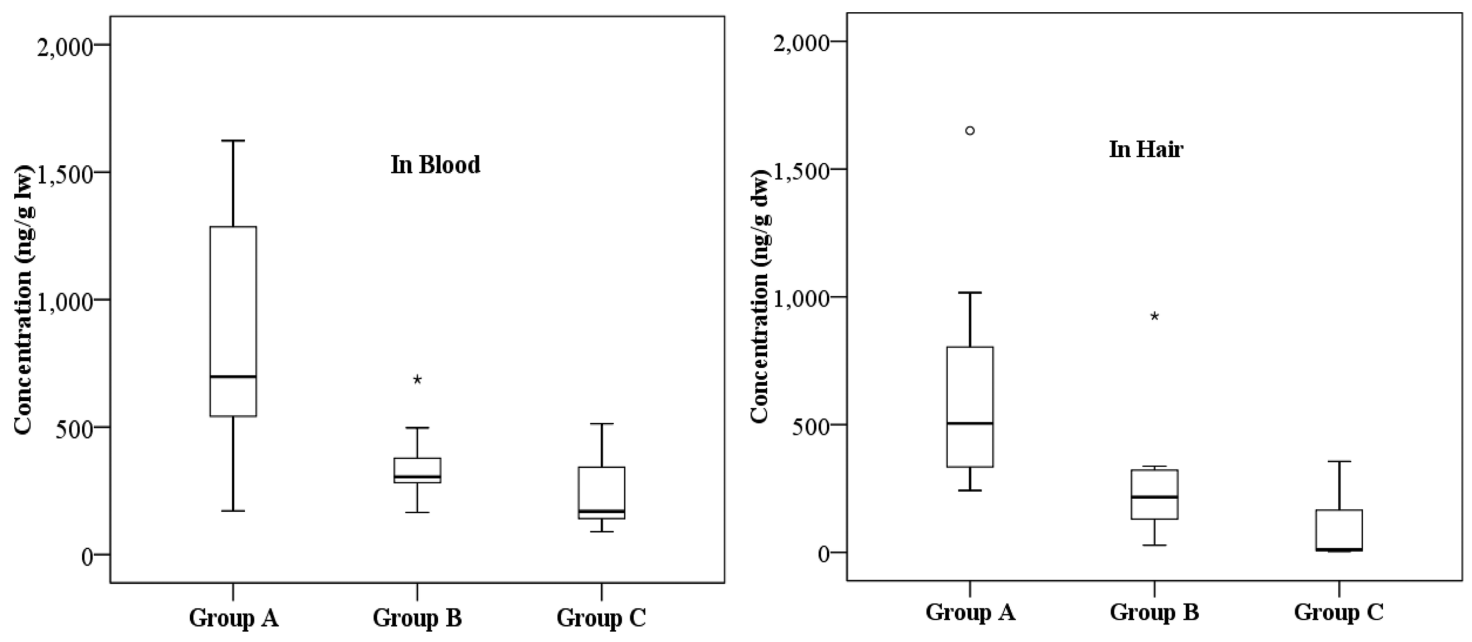

Figure 1. Comparison of DP levels in the human blood and hair samples.

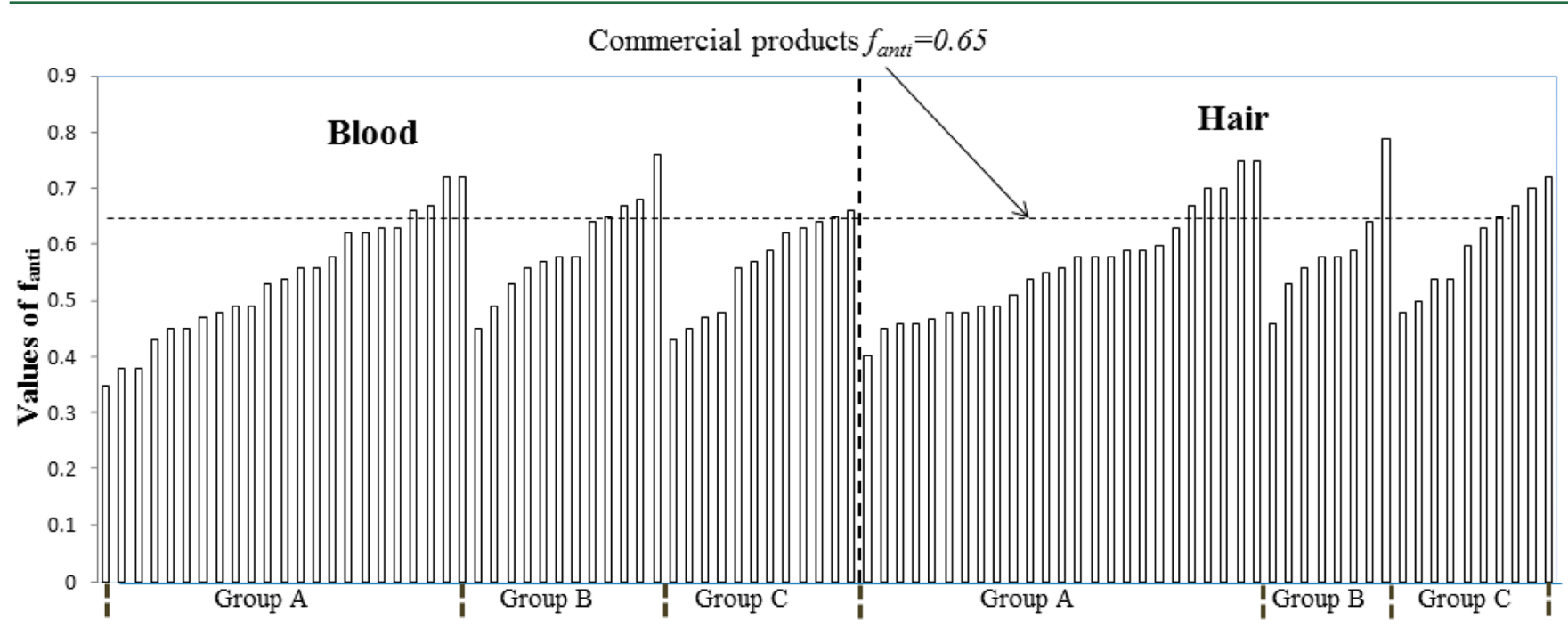

Figure 2. The $f_{\text {anti }}$ values in the blood and hair samples.

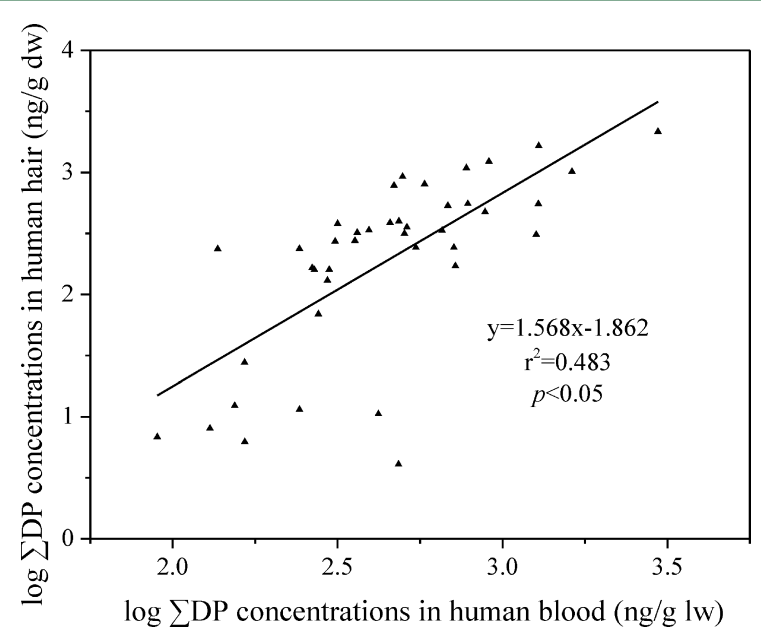

Figure 3. Correlation between the concentrations of $\sum \mathrm{DP}$ in the blood and hair.

$(S / N)=3$. The mean method detection limits for syn-DP and anti-DP were 0.846 and $0.592 \mathrm{ng} / \mathrm{g}$ lw in blood, 0.018 and $0.013 \mathrm{ng} / \mathrm{g} \mathrm{dw}$ in hair, respectively. All of the human blood and hair samples were spiked with internal standards. The average

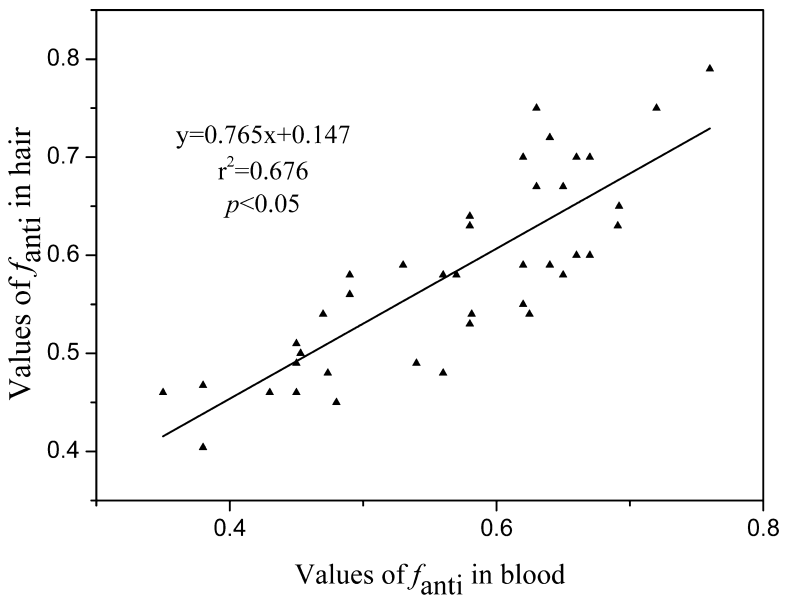

Figure 4. Correlation between the $f_{\text {anti }}$ values in the blood and hair.

recoveries of ${ }^{13} \mathrm{C}_{12}$-PCB-209 in the samples ranged from $86.3 \%$ to $114.6 \%$ in blood and from $82.2 \%$ to $121.8 \%$ in hair, respectively. One laboratory blank was processed paralleled with each batch of 10 samples, and no DP isomers were detected in these blanks. 
Table 1. Concentrations of Two Isomers of DP, $\sum D P$ and $f_{\text {anti }}$ in the Human Blood (ng/g lw) and Hair (ng/g dw) among the Three Groups

\begin{tabular}{|c|c|c|c|c|c|c|}
\hline & \multicolumn{2}{|c|}{ group A } & \multicolumn{2}{|c|}{ group B } & \multicolumn{2}{|c|}{ group C } \\
\hline & blood $(n=23)$ & hair $(n=22)$ & blood $(n=12)$ & hair $(n=11)$ & blood $(n=12)$ & hair $(n=10)$ \\
\hline$s y n-\mathrm{DP}$ & $386(80.4-1242)$ & $279(89.1-799)$ & $143(69.4-302)$ & $102(13.0-379)$ & $106(47.6-252)$ & $28.5(1.88-142)$ \\
\hline anti-DP & $471(90.6-1716)$ & $158(82.3-1360)$ & $207(95.8-385)$ & $158(14.7-545)$ & $207(42.2-339)$ & $53.3(2.20-213)$ \\
\hline$\sum \mathrm{DP}$ & $857(171-2958)$ & $260(171-2159)$ & $350(165-687)$ & $260(27.7-924)$ & $243(89.8-513)$ & $81.7(4.08-356)$ \\
\hline$f_{\text {anti }}$ & $0.54(0.35-0.72)$ & $0.56(0.48-0.63)$ & $0.60(0.53-0.76)$ & $0.59(0.46-0.79)$ & $0.61(0.43-0.69)$ & $0.60(0.48-0.79)$ \\
\hline STDEV & 0.108 & 0.102 & 0.087 & 0.081 & 0.076 & 0.084 \\
\hline
\end{tabular}

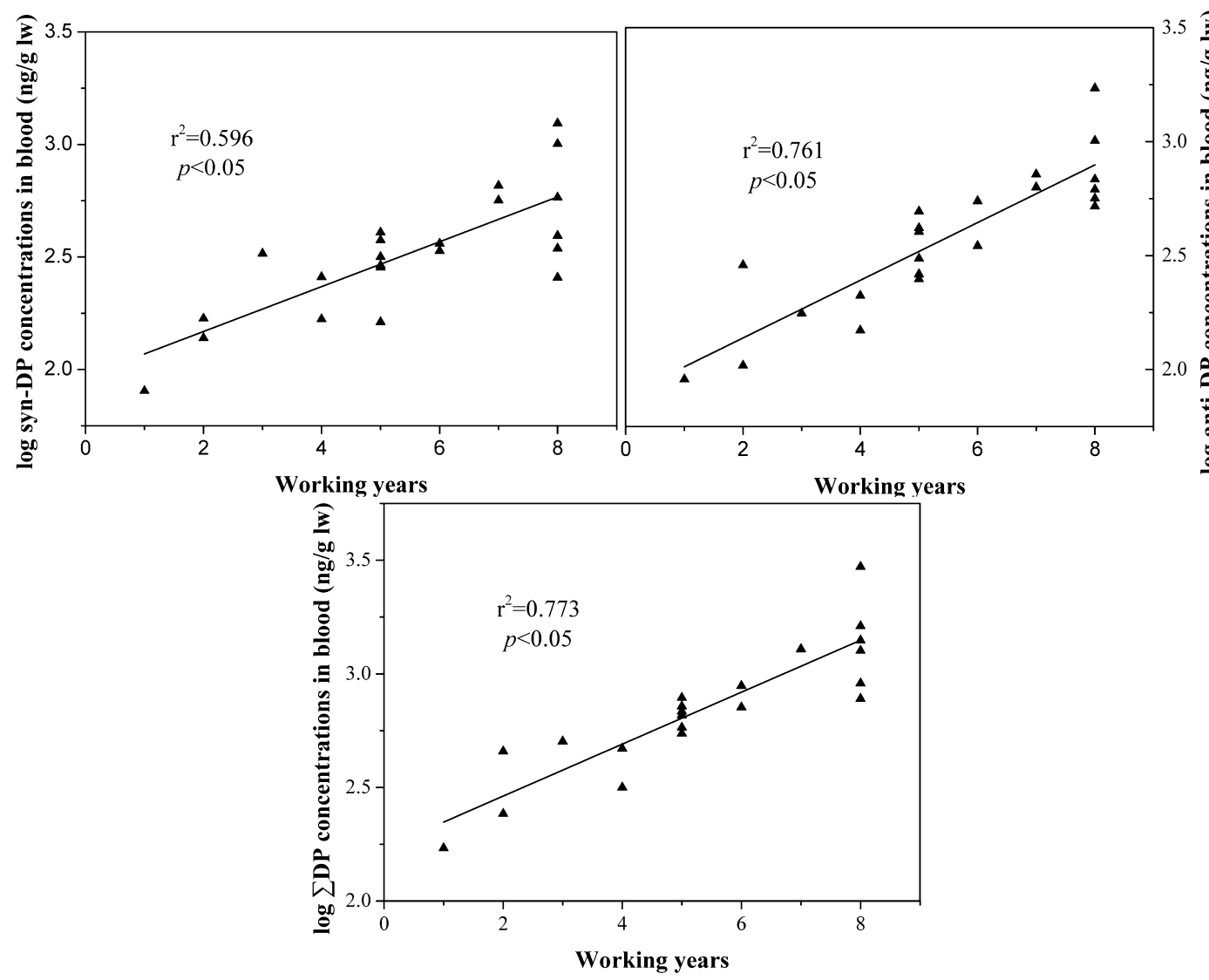

Figure 5. Correlation between the concentrations of syn-DP, anti-DP, and $\sum \mathrm{DP}$ in human blood and working years in DP plant.

\section{RESULTS AND DISCUSSION}

DP in the Human Blood. DP was detected in all 47 blood samples (Table 1). The concentrations of $\sum D P$ ranged from 89.8 to $2958 \mathrm{ng} / \mathrm{g} \mathrm{lw}$ (median: $456 \mathrm{ng} / \mathrm{g} \mathrm{lw}$ ), which were more than 10 times higher in comparison with that reported by Ren et al., ${ }^{27}$ where the concentrations were $7.8-465 \mathrm{ng} / \mathrm{g} \mathrm{lw}$ (median: $42.6 \mathrm{ng} / \mathrm{g} \mathrm{lw}$ ) in human serum in e-waste recycling workers. The general distribution of DP concentrations showed a declining trend as follow: Group A (171 to $2958 \mathrm{ng} / \mathrm{g} \mathrm{lw}$, mean $857 \mathrm{ng} / \mathrm{g} \mathrm{lw}$ ) > Group B (165 to $687 \mathrm{ng} / \mathrm{g}$ lw, mean 350 $\mathrm{ng} / \mathrm{g} \mathrm{lw})>$ Group C (89.8 to $513 \mathrm{ng} / \mathrm{g} \mathrm{lw}$, mean $243 \mathrm{ng} / \mathrm{g} \mathrm{lw})$ (Figure 1). Significant differences were observed between the DP concentrations in Group A and the other two groups (A vs $\mathrm{B}, p=0.014$; A vs $\mathrm{C}, p=0.023$ ), whereas no such relationships were found between Group B and C $(p=0.457)$.

The anti-DP fractional abundance is generally used to illustrate the fate and distribution of DP in the environment, which is defined as follows: ${ }^{15}$

$$
f_{\text {anti }}=[\text { anti-DP }] /([\text { anti-DP }]+[\text { syn-DP }])
$$

$f_{\text {anti }}$ value is not constant in commercial products, of which the variation was from 0.60 to $0.80 .^{29}$ The mean values of $f_{\text {anti }}$ of the technical DPs collected from the plant were $0.68 \pm 0.01$ $(n=4)$.

In this study, the overall $f_{\text {anti }}$ values in blood ranged from 0.35 to 0.76 (mean $0.56 \pm 0.10$ ), and the mean $f_{\text {anti }}$ values were 0.54 , 0.60 , and 0.61 for Groups A, B, and C, respectively (Table 1). The $f_{\text {anti }}$ values in Group A showed a relatively lower mean value, however, there was no significant difference observed between every two groups. The range of $f_{\text {anti }}$ values was comparable to the previous study by Ren et al. (an $f_{\text {anti }}$ mean of 0.57 in Guiyu and 0.63 in control area Haojiang), ${ }^{27}$ while a significant difference were observed for $f_{\text {anti }}$ values between e-waste recycling area and control area in that study.

DP in Human Hair. Both DP isomers were found in all 43 hair samples (Table 1). The concentrations of $\sum D P$ ranged between 4.08 and $2159 \mathrm{ng} / \mathrm{g} \mathrm{dw}$. Similar to the distribution trend in human blood samples, the concentrations showed the highest level in Group A (171 to $2159 \mathrm{ng} / \mathrm{g} \mathrm{dw}$, mean $667 \mathrm{ng} / \mathrm{g} \mathrm{dw}$ ), followed by Group B (27.7 to $337 \mathrm{ng} / \mathrm{g}$ dw with an exception 

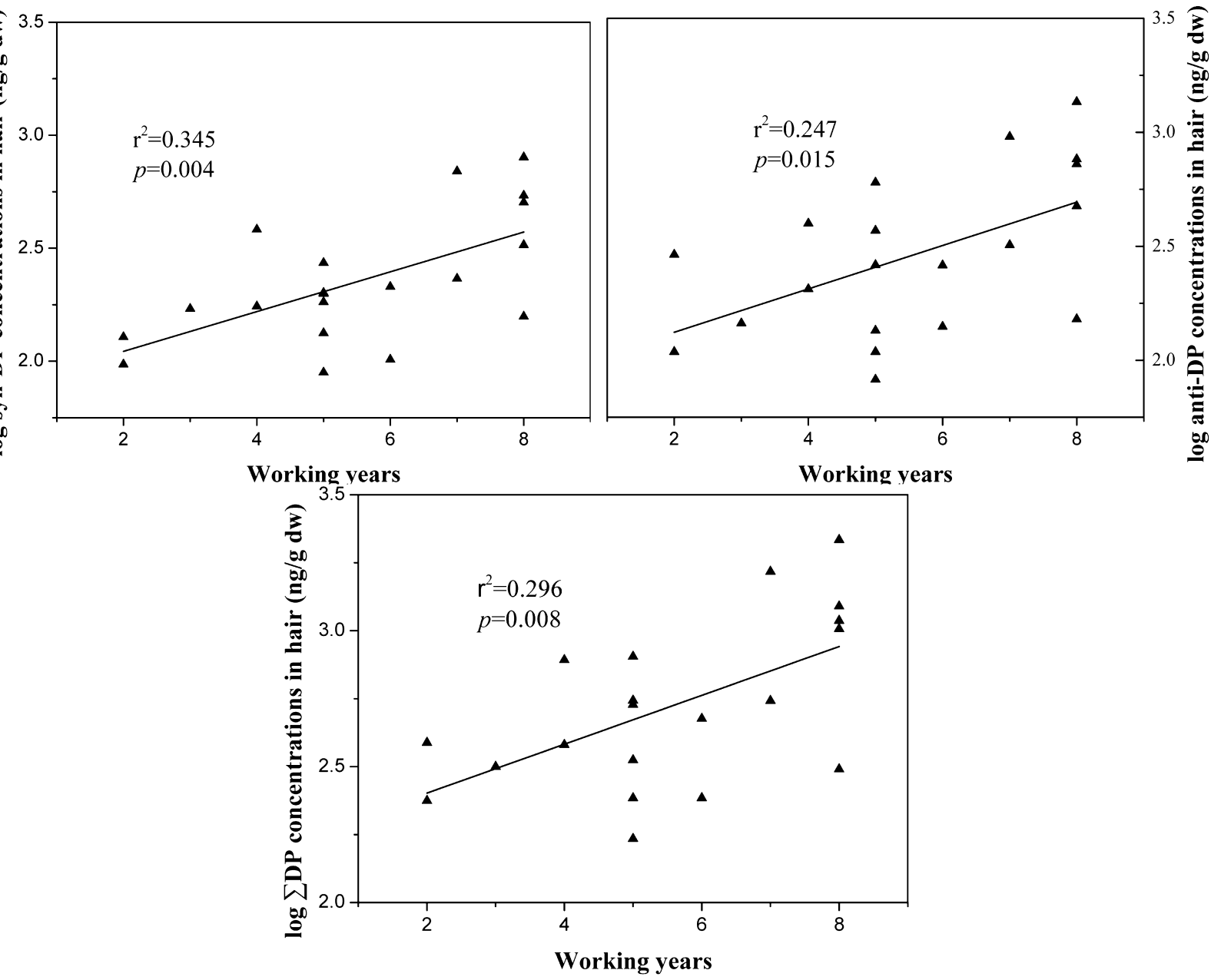

Figure 6. Correlation between the concentrations of syn-DP, anti-DP, and $\sum \mathrm{DP}$ in human hair and working years in DP plant.

of $924 \mathrm{ng} / \mathrm{g} \mathrm{dw}$ ), and Group C (4.08 to $236 \mathrm{ng} / \mathrm{g} \mathrm{dw}$ with an exception of $356 \mathrm{ng} / \mathrm{g} \mathrm{dw}$ ). Significant differences were also obtained for the DP concentrations between Group A and the other two groups (A vs B, $p=0.033$; A vs $\mathrm{C}, p=0.030$; B vs C, $p=0.967)$, which was consistent with the observation in the blood samples. The DP levels in the hair samples were much higher than the results from a previous study where DP levels were investigated in an e-waste recycling area (mean $15.4 \mathrm{ng} / \mathrm{g} \mathrm{dw}$ and $6.08 \mathrm{ng} / \mathrm{g} \mathrm{dw}$ for the workers engaged in e-waste recycling and other residents, respectively) and other areas (mean $1.03 \mathrm{ng} / \mathrm{g} \mathrm{dw}$ and $0.87 \mathrm{ng} / \mathrm{g} \mathrm{dw}$ in the rural and urban areas) in south China. ${ }^{28}$

The values of $f_{\text {anti }}$ in the hair samples ranged from 0.40 to 0.79 (mean $0.54 \pm 0.09$ ), and the mean values in each group were 0.56, 0.59, and 0.60 for Group A, Group B and Group C, respectively. The distribution of $f_{\text {anti }}$ values showed a very similar pattern to the blood samples, and no significant difference was observed between every two groups. A previous study ${ }^{28}$ in an e-waste recycling area suggested that $f_{\text {anti }}$ values in human hair $(0.55 \pm 0.11)$ were significantly lower in the control areas, which was comparable to that in the present study.

Possible Stereoselective Biotransformation of DP. The $f_{\text {anti }}$ values are generally used to assess possible stereoselective biotransformation of two DP isomers. ${ }^{4,15}$ The reported $f_{\text {anti }}$ values in air was constant, comparable to the value in the commercial product. ${ }^{18}$ Furthermore, the $f_{\text {anti }}$ values in other environmental matrixes, such as tree bark, were quite similar and remained relatively constant to that in DP commercial products over a distance about $1000 \mathrm{~km}$ from a manufacturing source. ${ }^{22}$ However, previous studies on aquatic biota such as smelt, diporeia, ${ }^{15}$ and alewife ${ }^{4}$ in Lake Ontario showed that synDP could be stereoselectively enriched or accumulated, which led to lower $f_{\text {anti }}$ values in biotic samples. In this study, lower $f_{\text {anti }}$ values were found in human blood and hair from occupational exposed workers, suggesting that stereoselective bioaccumulation or biotransformation of DP could occur in human body. Previous study also observed lower $f_{\text {anti }}$ values in serum from e-waste recycling workers and attributed this result to decomposition of the DP isomers during burning of e-wastes. ${ }^{27}$ The low $f_{\text {anti }}$ values in occupationally exposed workers in our study indicated that syn-DP may be stereoselectively enriched or accumulated. However, this needs to be further studied.

Relationships between DP Concentrations in the Blood and Hair Samples. A significantly positive relationship $(p<0.05)$ was obtained between the logarithmic values of concentrations in the paired blood and hair samples (Figure 3). This was consistent with the observation by Zheng and coworkers in an e-waste recycling area in south China, in which a similar relationship was obtained between DP concentrations in dust and hair samples, suggesting that hair analysis could be a valid screening tool for assessing human DP exposure. ${ }^{28}$ Furthermore, the relationship between the $f_{\text {anti }}$ values in the blood and hair samples also showed a significantly positive correlation $(p<0.05)$ with an $r^{2}$ value of 0.68 (Figure 4$)$, which 
indicated a very similar distribution pattern among the paired samples.

Correlation between DP Levels and Working Years. The relations between DP concentrations and age, gender, and working years were also investigated in this study. The average age of 48 participants was 42 years old (ranged from 32 to 55), in which female participants were 14 , and males were 34 . No correlations were observed between the DP levels in blood (hair) among age and gender, whereas significantly positive correlations were found for the logarithmic concentrations of syn-DP, anti-DP, and $\sum \mathrm{DP}$ in the human blood and hair samples against the working years in Group A (Figure 5 and 6). The result showed an evident bioaccumulation of DP among the occupationally exposed group along with exposure time, which suggested that occupational exposure could increase the risk of higher human DP levels. Additionally, the concentrations in blood samples showed stronger positive correlation against the working years $\left(r^{2}: 0.60-0.76\right)$ compared with those in hair $\left(r^{2}: 0.25-0.34\right)$. Because of easy and noninvasive sampling, hair is still a suitable bioindicator to assess the risk of DPs exposure.

In this work, we found that direct occupationally exposed workers showed higher levels of DP in their blood and hair compared to control groups. Whether or not these elevated levels could lead to adverse health effects is currently unclear. Further studies are therefore needed in order to investigate potential long-term risks to occupational population.

\section{AUTHOR INFORMATION}

\section{Corresponding Author}

*Tel/Fax: +8610-62849818; e-mail: qhzhang@rcees.ac.cn.

\section{Notes}

The authors declare no competing financial interest.

\section{ACKNOWLEDGMENTS}

This study was financially supported by National Natural Science Foundation of China (41276195 and 21107122) and Chinese Academy of Sciences (YSW2013B01).

\section{REFERENCES}

(1) Pakalin, S.; Cole, T.; Steinkellner, J.; Nicolas, R.; Tissier, C.; Munn, S.; Eisenreich, S. Review on production processes of decabromodiphenyl ether (DecaBDE) used in polymeric applications in electrical and electronic equipment, and assessment of the availability of potential alternatives to DecaBDE. EUR 22693 EN. European Commission; 2007. ISSN:0013-936Xhttp://ecb.jrc.ec. europa.eu/documents/Existing-Chemicals/.

(2) Ren, N. Q.; Sverko, E.; Li, Y. F.; Zhang, Z.; Harner, T.; Wang, D. G.; Wan, X. N.; McCarry, B. E. Levels and isomer profiles of dechlorane plus in Chinese air. Environ. Sci. Technol. 2008, 42 (17), 6476-6480.

(3) De la Torrea, A.; Sverko, E.; Alaee, M.; Martíneza, M. A. Concentrations and sources of Dechlorane Plus in sewage sludge. Chemosphere 2011, 82 (5), 692-697.

(4) Tomy, G. T.; Pleskach, K.; Ismail, N.; Whittle, D. M.; Helm, P. A.; Sverko, E.; Zaruk, D.; Marvin, C. H. Isomers of dechlorane plus in Lake Winnipeg and Lake Ontario food webs. Environ. Sci. Technol. 2007, 41 (7), 2249-2254.

(5) Tomy, G. T.; Thomas, C. R.; Zidane, T. M.; Murison, K. E.; Pleskach, K.; Hare, J.; Arsenault, G.; Marvin, C. H.; Sverko, E. Examination of isomer specific bioaccumulation parameters and potential in vitro hepatic metabolite of syn- and anti-Dechlorane Plus isomers in juvenile rainbow trout (Oncorhynchus mykiss). Environ. Sci. Technol. 2008, 42 (15), 5562-5567.
(6) Wu, J. P.; Zhang, Y.; Lou, X. J.; Wang, J.; Chen, S. J.; Guan, Y. T.; Mai, B. X. Isomer-specific bioaccumulation and trophic transfer of Dechlorane Plus in the freshwater food web from a highly contaminated site, South China. Environ. Sci. Technol. 2010b, 44 (2), 606-611.

(7) Jia, H.; Sun, Y.; Liu, X.; Yang, M.; Wang, D.; Qi, H.; Shen, L.; Sverko, E.; Reiner, E. J.; Li, Y. F. Concentration and bioaccumulation of dechlorane compounds in coastal environment of Northern China. Environ. Sci. Technol. 2011, 45 (7), 2613-2618.

(8) Shen, L.; Reiner, E. J.; MacPherson, K. A.; Kolic, T. M.; Sverko, E.; Helm, P. A.; Bhavsar, S. P.; Brindle, I. D.; Marvin, C. H. Identification and screening analysis of halogenated norbornene flame retardants in the Laurentian Great Lakes: Dechloranes 602, 603, and 604. Environ. Sci. Technol. 2010, 44 (2), 760-766.

(9) US EPA, United States Environmental Protection Agency. High Production Vol. (HPV) Challenge Program; 2004; Available at: http://www.epa.gov/HPV/ pubs/summaries/dechlorp/c15635tp.pdf (last accessed October 2012).

(10) Muir, D. C. G.; Howard, P. H. Are there other persistent organic pollutants? A challenge for environmental chemists. Environ. Sci. Technol. 2006, 40 (23), 7157-7166.

(11) Möller, A.; Xie, Z.; Sturm, R.; Ebinghaus, R. Large-scale distribution of dechlorane plus in air and seawater from the Arctic to Antarctica. Environ. Sci. Technol. 2010, 44 (23), 8977-8982.

(12) OxyChem. Dechlorane Plus Manual, Ver: 7-27-07, 2007; Available at: http://www.oxy.com/OurBusinesses/Chemicals/ Products/Documents/dechloraneplus/dechlorane_plus.pdf (last accessed october 2012).

(13) Brock, W. J.; Schroeder, R. E.; McKnight, C. A.; Vansteenhouse, J. L.; Nyberg, J. M. Oral repeat dose and reproductive toxicity of the chlorinated flame retardant Dechlorane Plus. Int. J. Toxicol. 2010, 29 (6), 582-593.

(14) Wu, B.; Liu, S.; Guo, X.; Zhang, Y.; Zhang, X.; Li, M.; Cheng, S. Responses of mouse liver to dechlorane plus exposure by integrative transcriptomic and metabonomic studies. Environ. Sci. Technol. 2012, 46 (19), 10758-10764.

(15) Hoh, E.; Zhu, L.; Hites, R. A. Dechlorane Plus, a chlorinated flame retardant, in the Great Lakes. Environ. Sci. Technol. 2006, 40 (4), 1184-1189.

(16) Sverko, E.; Tomy, G. T.; Reiner, E. J.; Li, Y. F.; McCarry, B. E.; Arnot, J. A.; Law, R. J.; Hites, R. A. Dechlorane plus and related compounds in the environment: a review. Environ. Sci. Technol. 2011, 45 (12), 5088-5098.

(17) Xian, Q. M.; Siddique, S.; Li, T.; Feng, Y. L.; Takser, L.; Zhu, J. P. Sources and environmental behavior of dechlorane plus-A review. Environ Int. 2011, 37 (7), 1273-1284.

(18) Wang, D. G; Yang, M.; Qi, H.; Sverko, E.; Ma, W. L; Li, Y. F; Alaee, M.; Reiner, E. J.; Shen, L. An Asia-specific source of Dechlorane Plus: Concentration, isomer profiles, and other related compounds. Environ. Sci. Technol. 2010, 44 (17), 6608-6613.

(19) Wang, B.; Iino, F.; Huang, J.; Lu, Y.; Yu, G.; Morita, M. Dechlorane Plus pollution and inventory in soil of Huai'an City, China. Chemosphere 2010, 80 (11), 1285-1290.

(20) Venier, M.; Hites, R. A. Flame retardants in the atmosphere near the Great Lakes. Environ. Sci. Technol. 2008, 42 (13), 4745-4751.

(21) Qiu, X. H; Marvin, C. H.; Hites, R. A. Dechlorane plus and other flame retardants in a sediment core from Lake Ontario. Environ. Sci. Technol. 2007, 41 (17), 6014-6019.

(22) Qiu, X. H.; Hites, R. A. Dechlorane Plus and other flame retardants in tree bark from the northeastern United States. Environ. Sci. Technol. 2008, 42 (1), 31-36.

(23) Guerra, P.; Fernie, K.; Jiménez, B.; Pacepavicius, G.; Shen, L.; Reiner, E J.; Eljarrat, E.; Barcelló, D.; Alaee, M. Dechlorane Plus and related compounds in peregrine falcon (Falco peregrines) eggs from Canada and Spain. Environ. Sci. Technol. 2011, 45 (4), 1284-1290.

(24) Gauthier, L. T.; Hebert, C. E.; Weseloh, D. V. C.; Letcher, R. J. Current-use flame retardants in the eggs of herring gulls (Larus argentatus) from the Laurentian Great Lakes. Environ. Sci. Technol. 2007, 41 (13), 4561-4567. 
(25) Gauthier, L. T.; Letcher, R. J. Isomers of Dechlorane Plus flame retardant in the eggs of herring gulls (Larus argentatus) from the Laurentian Great Lakes of North America: Temporal changes and spatial distribution. Chemosphere 2009, 75 (1), 115-120.

(26) Siddique, S.; Xian, Q. M.; Abdelouahab, Nadia.; Takser, L.; Phillips, S. P.; Feng, Y. L.; Wang, B.; Zhu, J. P. Levels of dechlorane plus and polybrominated diphenylethers in human milk in two Canadian cities. Environ Int. 2012, 39 (1), 50-55.

(27) Ren, G.; Yu, Z.; Ma, S.; Li, H.; Peng, P.; Sheng, G.; Fu, J. Determination of Dechlorane Plus in serum from electronics dismantling workers in south China. Environ. Sci. Technol. 2009, 43 (24), 9453-9457.

(28) Zheng, J.; Wang, J.; Luo, X. J.; Tian, M.; He, L. Y.; Yuan, J. G.; Mai, B. X.; Yang, Z. Y. Dechlorane Plus in human hair from an e-waste recycling area in south China: Comparison with dust. Environ. Sci. Technol. 2010, 44 (24), 9298-9303.

(29) Ben, Y. J.; Li, X. H.; Yang, Y. L.; Li, L.; Di, J. P.; Wang, W. Y.; Zhou, R. F.; Xiao, Ke.; Zheng, M. Y.; Tian, Y.; Xu, X. B. Dechlorane Plus and its dechlorinated analogs from an e-waste recycling center in maternal serum and breast milk of women in Wenling, China. Environ. Pollut. 2013, 173, 176-181.

(30) Liu, H. X.; Zhang, Q. H.; Cai, Z. W.; Li, A.; Wang, Y. W.; Jiang, G. B. Separation of polybrominated diphenyl ethers, polychlorinated biphenyls, polychlorinated dibenzo-p-dioxins and dibenzo-furans in environmental samples using silica gel and florisil fractionation chromatography. Anal. Chim. Acta 2006, 557 (1), 314-320.

(31) Johansen, H. R.; Alexander, J.; Rossland, O. J.; Planting, S.; Løvik, M.; Gaarder, P. I.; Gdynia, W.; Bjerve, K. S.; Becher, G. PCDDs, PCDFs, and PCBs in human blood in relation to consumption of crabs from a contaminated Fjord area in Norway. Environ. Health Perspec. 1996, 104 (7), 756-764.

(32) Link, B.; Gabrio, T.; Zoellner, I.; Piechotowski, I.; Paepke, O.; Herrmann, T.; Kennel, A. F.; Maisner, V.; Schick, K. H.; Schrimpf, M.; Schwenk, M.; Wuthe, J. Biomonitoring of persistent organochlorine pesticides, PCDD/PCDFs and dioxin-like PCBs in blood of children from South West Germany (Baden-Wuerttemberg) from 1993 to 2003. Chemosphere 2005, 58 (9), 1185-1201. 